\title{
Configurações
}

Revista de sociologia

\section{Práticas e visões dos profissionais de acolhimento nos processos de reunificação familiar: um estudo exploratório}

Practices and views of professionals in residential care about the processes of family reunification: an exploratory study

Pratiques et visions des professionnels de foyers d'accueil sur les processus de réunification familiale : une étude préliminaire

José Arizmendi e Ana Almeida

\section{OpenEdition}

\section{Journals}

\section{Edição electrónica}

URL: http://journals.openedition.org/configuracoes/7325

DOI: $10.4000 /$ configuracoes.7325

ISSN: 2182-7419

\section{Editora}

Centro de Investigação em Ciências Sociais

Edição impressa

Paginação: 73-89

ISSN: 1646-5075

\section{Refêrencia eletrónica}

José Arizmendi e Ana Almeida, « Práticas e visões dos profissionais de acolhimento nos processos de reunificação familiar: um estudo exploratório », Configurações [Online], 23 | 2019, posto online no dia 28 junho 2019, consultado o 30 junho 2019. URL : http://journals.openedition.org/configuracoes/7325 ; DOI : 10.4000/configuracoes.7325 
Arizmendi, José; Almeida; Ana - Práticas e visões dos profissionais de acolhimento nos processos de reunificação familiar: um estudo exploratório. Configurações, vol. 23, 2019, pp. 73- 89.

\title{
Práticas e visões dos profissionais de acolhimento nos processos de reunificação familiar: um estudo exploratório
}

\author{
JOSÉ ARIZMENDI* \\ Universidade do Minho \\ ANA ALMEIDA** \\ Centro de Investigação em Estudos da Criança (CIEC), Universidade do Minho
}

\section{Resumo}

As famílias com crianças e jovens em acolhimento residencial apresentam necessidades específicas ao longo do processo de reunificação familiar. Parte de um estudo mais alargado, este artigo apresenta exclusivamente as visões de uma subamostra de 27 profissionais, recolhidas através de grupos focais e entrevistas semiestruturadas. Com o objetivo de identificar a sua resposta às necessidades das famílias, esta investigação reuniu as perspetivas dos profissionais, analisando os seus comportamentos, procedimentos e atitudes. Os resultados revelam a necessidade de melhorar os recursos e de incluir as famílias, flexibilizando estratégias de participação e desenhando procedimentos de intervenção com as famílias para a melhora das suas competências.

Palavras-chave: Reunificação familiar, profissionais, acolhimento residencial, proteção da infância.

\footnotetext{
Abstract reunification: an exploratory study

*E-mail: josemfarizmendi@gmail.com

**E-mail: aalmeida@ie.uminho.pt
}

Practices and views of professionals in residential care about the processes of family

Families with children and youth in residential care present specific needs throughout the reunification process. As a part of larger research, this article just presents the views of a subsample of 27 professionals, collected in focus groups and semi-structured interviews. With the objective of identifying their response to the needs of families, this research gathers the perspectives of professionals, analyzing their behaviors, procedures and attitudes. The results show the need of improving resources and including 
families by making the strategies for participation more flexible and designing intervention procedures with families to improve their competences.

Keywords: Family reunification, professionals, residential care, child protection.

\section{Résumé}

Pratiques et visions des professionnels de foyers d'accueil sur les processus de réunification familiale : une étude préliminaire

Les familles avec enfants en foyers d'accueil présentent des besoins spécifiques tout au long du processus de réunification. Dans le cadre d'une recherche plus large, cet article présente seulement les points de vue de 27 professionnels, recueillis dans des groupes de discussion et des entrevues semi-structurées. Avec l'objectif d'identifier leur réponse aux besoins des familles, cette investigation combina les perspectives des professionnels, en analysant leurs comportements, procédures et attitudes. Les résultats montrent le besoin d'augmenter les ressources e d'intégrer les familles en rendant les stratégies de participation plus flexibles et en élaborant des procédures d'intervention avec les familles pour améliorer leurs compétences.

Mots-clés: Reunification familiale, professionnels, foyers d'accueil, protection de l'enfance.

\section{Introdução}

Em Portugal, no relatório CASA de 2016 (Instituto da Segurança Social, I.P., 2017) pode ler-se que, a reunificação familiar, seja esta em família nuclear ou alargada, é o projeto de vida definido para $42,4 \%$ (2787) das crianças e jovens em acolhimento residencial generalista ou especializado, registando-se uma subida relativamente a anos anteriores. Por sua vez, das 2513 crianças que cessaram o acolhimento no ano anterior, 64,7\% (1614) tinham regressado às suas famílias. Porém, os dados mostram que estes processos não excluíam fragilidades, se se atender a que entre as crianças e jovens que reentraram no sistema $71,6 \%$ (643) dos casos estavam a usufruir de medidas de apoio junto dos pais ou de outros familiares após a reunificação.

A reunificação familiar no sistema de proteção à criança na lei portuguesa (Lei n. ${ }^{\circ}$ 26/2018, de 05/07, que altera a Lei de Promoção e Proteção de Crianças e Jovens em Perigo, Lei no 147/99, de 01/09) refere-se ao regresso à família depois da aplicação de uma medida de acolhimento que implicou a separação da criança ou do jovem devida a uma situação de negligência ou maltrato. Nem todos os casos preveem a reunificação, mas sempre que ela é considerada supõe que se desencadeiem um conjunto de processos que facilitem e consolidem a mesma.

Entre as causas para o acolhimento, predominam as relativas à negligência: $4826(59,0 \%)$ crianças e jovens acolhidos em 2016 experimentaram falta de supervisão e acompanhamento familiar; 2618 (32,0\%) estiveram expostos a modelos parentais desviantes; $2583(31,60 \%)$ foram negligenciados nos 
cuidados de educação e 2381 (29,1\%) nos de saúde (Instituto da Segurança Social, I.P., 2017). O impacto das situações de perigo que conduzem ao acolhimento, as consequências da aplicação da medida no desenvolvimento das crianças, bem como os desafios que o acolhimento supõe à dinâmica da família e ao equilíbrio dos relacionamentos causam, cada um por si e combinadamente, enorme stresse e a sobrecarga a sistemas familiares já de si muito fragilizados (Balsells et al., 2015; Del Valle, 2009). Reverter este processo de fragilização, quando o projeto de vida é a reunificação familiar, implica o apoio aos pais durante o acolhimento com o objetivo de facilitar o regresso a casa da criança ou jovem, fortalecendo e promovendo as competências parentais fundamentais à satisfação das necessidades dos mais jovens, à melhoria da convivência familiar e das interações positivas entre pais e filhos.

\section{A avaliação, 0 acolhimento e os planos individuais de ação}

No que respeita à avaliação do risco psicossocial das famílias, as práticas profissionais mudaram substancialmente ao longo das últimas décadas. Durante muito tempo os protocolos de avaliação privilegiaram as características individuais das crianças e jovens, passando progressivamente a incluir informações do contexto familiar, mantendo-se, no entanto, o foco nos défices dos agregados familiares ao procurar estabelecer perfis de risco que permitissem a classificação e a intervenção (Martín et al., 2014). A necessidade de compreender as forças das famílias no contexto de uma avaliação compreensiva impõe-se com o aparecimento de novos instrumentos que permitem especificamente a avaliação de forças e recursos e resulta igualmente da centralidade que assumem os modelos de intervenção multidimensionais. O Framework for the Assessment for Children in Need and their Families (FACNF) desenvolvido pelo Department of Health do Reino Unido (2000) estabelece como eixos fundamentais na avaliação e intervenção: (1) as necessidades desenvolvimentais da criança; (2) as competências parentais para responder a essas necessidades e, (3) a influência da família alargada e de outros elementos contextuais (vizinhança, escola, comunidade).

Especificamente, no que toca às famílias e crianças implicadas em processos de acolhimento, os aspetos valorizados nos protocolos de avaliação influenciam os passos subsequentes. A comunicação da decisão do acolhimento por parte dos profissionais e posteriormente a entrada da criança no recurso residencial supõem habitualmente um desafio para o agregado familiar. Estes instantes aparecem tipicamente marcados pelas perdas materiais, emocionais e culturais, com um necessário processo de luto e a experiência do choque inicial tanto nas crianças como nos pais e mães, podendo inibir, por sua vez, uma compreensão realista dos motivos objetivos que levaram à separação (Balsells et al., 2014). 
A ponderação destes aspetos tem permitido reconhecer a necessidade de integrar a perceção das famílias acerca dos desafios a que terão de responder antes, durante e após o acolhimento. A este respeito, na linha de conceitualizações positivas, Lietz e Strength (2009) defendem que, nestes processos estão envolvidos capacidades e recursos semelhantes aos que habitualmente estão contemplados noutros processos resilientes e que passam sucessivamente pela ativação de estratégias de: (1) sobrevivência; (2) adaptação; (3) aceitação; (4) crescimento e, eventualmente, (5) a prestação de ajuda a outras famílias com crianças em acolhimento.

Neste sentido, os procedimentos da fase inicial do acolhimento devem incluir a familiarização da criança e da família com os profissionais, as outras crianças, as rotinas e os espaços da casa de acolhimento. Por sua vez, ao entrar no recurso residencial, conjuntamente às observações realizadas pelos educadores nos primeiros dias do acolhimento, é necessária uma avaliação diagnóstica ecológico-sistémica que combine de forma integrada as caraterísticas da criança e da família. Esta permitirá realizar um plano de ação específico, referido como Processo Socioeducativo Individualizado (PSEI).

No caso dos processos de reunificação, o PSEI deve contemplar a definição de objetivos, atividades e recursos na intervenção e a avaliação periódica dos mesmos, considerando especificamente a manutenção dos vínculos familiares, a colaboração da família, a resolução de situações de conflito, o apoio às competências de organização do ambiente familiar (estabilidade, afeto e proteção) e a melhoria das competências parentais. Nestas ações, a relação entre a casa de acolhimento, a criança e a família pode facilitar a intervenção de cariz psico e socioeducativa (Arizmendi e Almeida, 2017; Balsells et al., 2013; Del Valle e Bravo, 2007; Del Valle et al., 2012).

Porventura, a ausência de um modelo teórico de intervenção com famílias no contexto do acolhimento pode dificultar este trabalho de caráter psico e socioeducativo. Num estudo realizado por Bravo Arteaga e Del Valle (2001), a análise dos objetivos dos programas individuais de intervenção de 673 crianças e jovens em acolhimento residencial em Espanha, concluiu que embora as crianças e jovens mantivessem uma ligação estreita com os pais, existia pouco envolvimento por parte das famílias e escassas ações de intervenção familiar por parte dos profissionais, especialmente no caso dos adolescentes.

A qualidade do acolhimento residencial e da intervenção com as crianças e jovens neste tipo de recursos passa necessariamente pelo apoio sistemático prestado às famílias, o fomento da sua participação ao incluir os progenitores na vida da criança acolhida e o apoio ao desenvolvimento das aptidões parentais (Del Valle et al., 2012). 


\section{A intervenção junto da família antes e após a reunificação}

As visitas e os contactos têm sido uma prática comum no acolhimento residencial (Déprez e Wendland, 2015; Leathers, 2002). Estes contactos permitem manter os laços afetivos e reduzem o sentimento de abandono das crianças, mas os benefícios das visitas nem sempre são entendidos de forma unânime pelos profissionais e transformam-se com frequência num momento de avaliação mais do que de intervenção (Carnochan, Lee e Austin, 2013; Déprez e Wendland, 2015; Sen e Broadhurst, 2011).

Nos casos em que o projeto de vida passa pela reunificação familiar, os objetivos não podem ficar unicamente pela manutenção da relação e dos vínculos. Neste sentido, vários estudos sublinham a importância de as práticas profissionais estimularem a inclusão progressiva e continuada das famílias nas rotinas médicas, escolares, na compra de roupa e em outras decisões, optando por medidas que deem visibilidade ao papel da família no sucesso do acolhimento (Leathers, 2002).

Apesar de o processo de reunificação familiar parecer simples, a sua preparação não está isenta de desafios, sobretudo, quando está iminente o regresso à família (Balsells et al., 2015). As práticas profissionais assumem nesta fase um papel importante, nomeadamente, partilhando com os pais informações sobre o comportamento, os interesses e as aspirações da criança ou do jovem que possam ajudar a família a ajustar as expetativas, reforçar as competências parentais, reduzir a ansiedade e prevenir os problemas que possam surgir (Balsells et al., 2014; Del Valle, 2009).

Depois do período de acolhimento, é preciso um plano de apoio tanto para a criança como para os progenitores (Biehal, 2007; Knorth, Knot-dickscheit e Thoburn, 2016). Neste sentido, este plano de trabalho desafia os profissionais a explorar novas ações, reforçando a colaboração entre instituições e a criação de grupos de apoio aos pais (Maluccio e Ainsworth, 2003). Por sua vez, estas medidas vão ao encontro da necessidade de assegurar uma rede de apoio social tanto dentro como fora da família após a reunificação (Balsells et al., 2013, 2014; Lietz, Lacasse e Cacciatore, 2011).

\section{Metodologia}

O presente trabalho inscreve-se no contexto de um estudo mais alargado, de tipo qualitativo e exploratório, no qual se analisaram os discursos dos diferentes intervenientes nos processos de reunificação familiar. Neste artigo, o foco concentra-se no grupo dos profissionais com o objetivo de conhecer as suas perceções sobre as necessidades, procedimentos, práticas e atitudes relativas ao trabalho que desenvolvem no âmbito dos processos de reunificação familiar. Como hipóteses, considerou-se que, apesar do progressivo envolvimento das famílias no acolhimento, o trabalho profissional continua a focar-se nos 
défices, com uma intervenção fundamentalmente baseada nas visitas e pouca continuidade após a saída da criança ou do jovem da casa de acolhimento.

\section{1. Participantes}

A amostra de profissionais contou com 27 educadores e técnicos de 6 casas de acolhimento. A seleção dos participantes obedeceu a dois critérios previamente estabelecidos: 1) pertencer à equipa técnica ou educativa da casa de acolhimento; 2) trabalhar nas unidades de acolhimento no mínimo há 6 meses.

$\mathrm{Na}$ amostra de profissionais predominavam mulheres $(85,2 \%)$, com idades compreendidas entre os 24 e os 59 anos $(\mathrm{M}=38,3$; $\mathrm{SD}=8,91)$. Os papéis/ funções dentro da casa de acolhimento e as habilitações profissionais apresentaram-se positivamente correlacionados ( $\mathrm{rs}=.692, \mathrm{p}<.001)$. Concretamente, o grupo sem habilitações superiores $(44,4 \%)$ estava principalmente vinculado a funções educativas e ao acompanhamento diário das crianças e jovens, enquanto que o grupo dos licenciados ou formação superior desempenhava papéis de técnico ou coordenador. As principais áreas de formação dos profissionais eram em educação $(22,2 \%)$ e psicologia $(25,9 \%)$.

Quadro 1: Características dos profissionais

\begin{tabular}{|c|c|}
\hline Caracteristicas & Profissionais $(N=27)$ \\
\hline \multicolumn{2}{|l|}{ Sexo } \\
\hline Masculino & $4(14,8 \%)$ \\
\hline Feminino & $23(85,2 \%)$ \\
\hline \multicolumn{2}{|l|}{ Idade } \\
\hline $20-29$ & $5(18,5 \%)$ \\
\hline $30-39$ & $9(33,3 \%)$ \\
\hline $40-49$ & $10(37,0 \%)$ \\
\hline $50-59$ & $3(11,1 \%)$ \\
\hline \multicolumn{2}{|c|}{ Experiência laboral (anos) } \\
\hline $1-5$ & $6(22,2 \%)$ \\
\hline $6-10$ & $7(25,9 \%)$ \\
\hline $11-15$ & $7(25,9 \%)$ \\
\hline $16-20$ & $6(22,2 \%)$ \\
\hline $21-25$ & $1(3,7 \%)$ \\
\hline \multicolumn{2}{|l|}{ Habilitações } \\
\hline Secundário & $12(44,4 \%)$ \\
\hline Licenciatura & $10(37,0 \%)$ \\
\hline Pós-graduação & $1(3,7 \%)$ \\
\hline Mestrado & $4(14,8 \%)$ \\
\hline \multicolumn{2}{|l|}{ Área de formação } \\
\hline Educação & $6(22,2 \%)$ \\
\hline Psicologia & $7(25,9 \%)$ \\
\hline Trabalho social & $3(11,1 \%)$ \\
\hline Outro & $7(25,9 \%)$ \\
\hline Sem definir & $414,8 \%)$ \\
\hline \multicolumn{2}{|c|}{ Funçôes na casa de acolhimento } \\
\hline Educador & $14(51,9 \%)$ \\
\hline Técnico & $8(29,6 \%)$ \\
\hline Coordenador & $5(18,5 \%)$ \\
\hline
\end{tabular}


As casas de acolhimento, pertencentes ao distrito de Braga, estavam localizadas nos concelhos de Braga (4 casas) e Barcelos (2 casas). Excetuando uma das casas, as restantes estavam situadas em contextos urbanos. Atendendo ao número de crianças/jovens e as suas idades, a amostra incluiu casas de diferente dimensão e com um amplo leque de idades. Apesar de os adolescentes entre os 12 e 18 anos serem o grupo maioritário, 2 casas (33,3\%) acolhiam também crianças menores de 6 anos.

Quadro 2: Características das casas de acolhimento

\begin{tabular}{|c|c|}
\hline Caracteristicas & Casas $(N=6)$ \\
\hline \multicolumn{2}{|l|}{ Dimensão } \\
\hline Pequena dimensđ̃o (até 12 crianças) & $2(33,3 \%)$ \\
\hline Mediana dimensão (entre 12 e 30 crianças) & $1(16,7 \%)$ \\
\hline Grande dimensão (mais de 30 crianças) & $3(50,0 \%)$ \\
\hline \multicolumn{2}{|l|}{$\begin{array}{l}\text { Idades das crianças acolhidas" } \\
\text { "uma mesma casa ter criaņ̧ai de diferemes idades }\end{array}$} \\
\hline $0-6$ anos & $2(33,3 \%)$ \\
\hline $6-12$ anos & $5(83,3 \%)$ \\
\hline $12-18$ anos & $6(100,0 \%)$ \\
\hline+18 anos & $3(50,0 \%)$ \\
\hline \multicolumn{2}{|l|}{ Concelho } \\
\hline Braga & $4(66,6 \%)$ \\
\hline Barcelos & $2(33,3 \%)$ \\
\hline \multicolumn{2}{|l|}{ Localização } \\
\hline Ámbito urbano & $5(83,3 \%)$ \\
\hline Ámbito rural & $1(16,7 \%)$ \\
\hline
\end{tabular}

\section{2. Instrumentos}

Foi usada uma metodologia mista de recolha de dados com grupos focais e entrevistas semiestruturadas. Para os grupos focais procedeu-se à elaboração de um guião com cinco seções: as quatro primeiras relacionadas com as diferentes fases do processo de reunificação e a quinta sobre a consciência das mudanças realizadas. Cada seção incluía entre 4 e 8 itens. O guião foi posteriormente adaptado para as entrevistas semiestruturadas. A administração de cada grupo focal demorou aproximadamente 80 minutos e, a entrevista, 50 minutos. Adicionalmente, foi incluído um breve questionário sociodemográfico para a caracterização sociodemográfica da amostra. 


\section{3. Procedimentos}

$\mathrm{O}$ pedido de colaboração às casas de acolhimento que participaram na amostra foi realizado junto das técnicas do Núcleo de Infância e Juventude do Centro Distrital do Instituto da Segurança Social, I.P. Nas 6 casas que responderam favoravelmente ao pedido, os profissionais que atendiam aos critérios de seleção, disponibilizaram-se para o estudo. A seguir, procedeu-se à recolha de dados, através da realização de 5 grupos focais e de 1 entrevista (ao não conseguir elementos suficientes para realizar um grupo focal nessa casa). Posteriormente, o material foi transcrito e feita a análise de conteúdo utilizando o software Atlas.ti 10.1.51 recorrendo a um modelo de análise dedutivo e indutivo que teve na base o referencial teórico acerca das diferentes fases do processo de reunificação. Quer a codificação dos dados recolhidos nas entrevistas, quer a construção das categorias emergiram da teoria e dos temas considerados relevantes na análise do conteúdo das entrevistas.

\section{4. Confiabilidade e credibilidade}

A construção dos guiões contou com a colaboração de dois investigadores com experiência na área e, posteriormente, foram revistos por profissionais não participantes no estudo. A recolha de dados foi completada com notas de campo e o processo de codificação seguiu critérios de uniformidade, precisão e diferença.

Para garantir a qualidade da codificação, dois investigadores juniores a quem foi dada informação sobre o sistema de categorias e respetiva categorização, realizaram a análise de conteúdo de modo independente, calculando-se em seguida o acordo inter-juízes (Intercoder Reliability ICR) com o recurso ao alfa de Krippendorff como medida de diferença das codificações (Hayes e Krippendorff, 2007). O coeficiente de acordo (.72) foi razoavelmente positivo.

\section{5. Ética}

Previamente à recolha de dados, foi obtido o parecer favorável à realização do estudo pela Subcomissão de Ética para as Ciências Sociais e Humanas (SECSH) da Universidade do Minho. Em conformidade com as normas de confidencialidade e anonimato, os participantes foram informados dos objetivos e finalidades da investigação, subescrevendo o seu consentimento informado à participação voluntária para o efeito.

\section{Resultados}

\section{1. A consciência do acolhimento e a integração}

Os resultados indicam que, na perspetiva dos profissionais, a preparação e o acolhimento das crianças e dos jovens está muito relacionada com a gestão prévia que foi realizada pelos técnicos gestores externos que acompanharam 
o caso da família. Na opinião dos profissionais das casas de acolhimento, a chegada à unidade residencial acontece muito tarde, dificultando a intervenção. Por sua vez, nesses instantes iniciais, deparam-se com os inconvenientes dos acolhimentos realizados de emergência, em que a margem de tempo para a preparação da entrada ou até a própria informação recebida, são escassas.

A partir do discurso dos educadores é possível observar que existe um esforço e interesse na integração da criança ou do jovem na casa de acolhimento, que não decorrem da implementação efetiva de protocolos de ação, mas antes de um conhecimento profissional de boas práticas. É valorizado especialmente o papel que têm os pares para facilitar a adaptação da criança à casa.

Nos discursos dos profissionais transparece um maior esforço no trabalho e adaptação da criança em relação aos progenitores. Contudo, é possível observar que as ações desenvolvidas diferem em função da idade. Especialmente no caso das crianças mais novas, os profissionais das casas de acolhimento referem sentir maior resistência da família, pois estas tendem a identificar o recurso residencial com aquele que realiza a retirada, expressando medos e receios de que a criança não discrimine os pais das figuras de cuidadores técnicos e educadores.

Nós somos a instituição de acolhimento. Nós estamos aqui na posição de quem recebe. Não, não somos nós que fazemos a retirada. E a partir do momento que eles percebem que somos só e apenas a instituição de acolbimento, que não somos nós a instituição que os retirou, as coisas acalmam; e sossegam. (Coordenadora)

Os profissionais, especialmente os técnicos, referem que as famílias têm consciência da necessidade de algum tipo de apoio, mas o facto de estas não terem uma visão realista das necessidades do contexto familiar e da sua importância no bem-estar da criança, suscita resistências à colocação da criança numa casa de acolhimento. Parte dos esforços são referidos como de provisão de informação às crianças e aos pais/mães, assumindo que a compreensão será um processo posterior.

Quase nunca têm [consciência]. No meu ponto de vista, eu acho que eles não acabam por ter consciência que realmente têm esse problema e que as crianças precisam de sair de... do meio familiar. Eu acho que eles muitas vezes acabam por aceitar até, confiando nos técnicos, que a situação se vai resolver, mas dificilmente têm essa perceção que realmente não podem ter as crianças consigo. É um trabalho também que os técnicos têm que fazer. (Técnico) 
No entanto, os participantes também reconheceram que, pese embora seja dada informação às famílias, esta poderia ser mais completa, considerando que existem lacunas e necessidade de promover consensos e a aceitação das medidas por parte das crianças e dos progenitores. Neste sentido, os profissionais apontaram como um elemento crítico para a aceitação a informação objetiva sobre a duração das medidas, sendo a falta dela geradora da incerteza que muitas das crianças acolhidas experimentam. Segundo os profissionais, o prolongamento habitual da medida, frustrando as expectativas iniciais das famílias, pode causar nas crianças sentimentos de revolta e fracasso.

Depois, quando acaba a primeira medida, eles têm uma expectativa muito alta de saída e aí não saem e revoltam-se... Depois, com o prolongar do tempo; aí, eu acho, eles vão baixando as expectativas; veem que realmente as coisas não funcionam como eles tinham a expectativa que funcionassem, não é? O tempo é uma coisa que ninguém pode dizer: é assim! (Educadora)

\section{2. Os contactos e as visitas}

Os profissionais das casas consideram que as visitas das famílias são um elemento importante na intervenção que fazem junto da criança. Segundo referem, os contactos evitam o risco de desresponsabilização das famílias, embora reconheçam que, passados os primeiros momentos, é possível cair na rotina. Para tornar possíveis estes contactos, a maioria dos profissionais explicam que as casas flexibilizam as suas rotinas, embora o otimismo de algumas visões contraste com o realismo dos que reconhecem que existe uma necessidade de programar as visitas para não interferirem com as rotinas e ritmos próprios da intuição.

\footnotetext{
Portanto, é muito difícil, havendo aqui uma organização, de um momento para outro aparecer aqui alguém sem marcação, sem as coisas previamente organizadas para fazer uma visita. Então se for uma visita com supervisão, pior ainda. E, então, o que nós tentamos é alertar as famílias que têm que ligar para cá, marcar a visita, contactar a instituição... Tentamos que nunca sejam coisas marcadas para o dia. (Coordenadora)
}

$\mathrm{Na}$ visão dos profissionais, os primeiros contactos estão marcados por uma desconfiança inicial por parte dos progenitores. O envolvimento progressivo e o modo como são aceites as críticas e sugestões dos pais proporcionam uma aproximação progressiva.

Ao mesmo tempo, esta tentativa de envolvimento das famílias das crianças aparece em vários discursos matizada por uma visão pessimista sobre as 
possibilidades reais de transparência e colaboração com os progenitores. Neste sentido, alguns profissionais manifestam que subsistem dificuldades ao envolvimento dos pais nos processos das crianças, e surgem receios de que os pais possam dificultar a intervenção com as crianças.

A gente só pode ajudar quem quer ser ajudado. E há famílias que fazem tudo e mais alguma coisa para serem ajudados e há outras que fazem precisamente o inverso. Aquilo que é feito aqui é estragado quando vão de fim-de-semana, quando vão de férias... É assim, a gente não pode ajudar. (Educador)

$\mathrm{Na}$ opinião dos profissionais, as visitas e os contactos são importantes para o bem-estar da criança, mas são um recurso ambíguo e até paradoxal pelas repercussões não controláveis no estado emocional da criança, e que atribuem fundamentalmente ao momento da visita/contacto ser ou não ser preenchido por momentos positivos.

Eu acho que dá estabilidade emocional como eles vêm emocionalmente e como ficam durante a semana até à próxima visita. Acho que é o fundamental. Porque basta uma visita correr mal, eles ficarem desestabilizados, para durante a semana ser uma desgraça. Ou, o contrário. (Coordenadora)

\section{3. No caminho da reunificação}

Nesta etapa, conscientes das necessidades, os profissionais salientam a importância das mudanças familiares, considerando também a relevância de estas se tornarem consistentes. É visível que os momentos prévios à reunificação contribuem também para uma maior recetividade dos progenitores às indicações dos profissionais. Para este facto contribuem a maior frequência e duração das visitas ao agregado familiar e a inclusão dos progenitores nas rotinas escolares e médicas, especialmente nos atendimentos. Estes incentivos constituem as principais ferramentas indicadas pelos profissionais ao desenvolvimento de competências familiares.

Este trabalho, por vezes, torna-se difícil pela escassez de recursos para intervir junto da família e pela falta de planos individuais estruturados, condicionados ainda muitas vezes a imprevistos ou à falta de credibilidade que alguns profissionais depositam nos mesmos.

Os participantes dizem sentir dificuldades em conseguir que os pais cheguem a aderir aos planos de trabalho propostos. Na opinião dos profissionais, a acomodação dos pais com a situação de acolhimento desde que sentem que o 
filho está em segurança revela-se um problema, especialmente quando as crianças e jovens alimentam o desejo de regressar a casa e junto dos pais.

A experiência já nos disse que passado o choque inicial do acolhimento, depois há uma certa acomodação e, portanto, a criança até está bem, e já não é preciso mudar muito... (Coordenadora)

$\mathrm{Na}$ opinião dos técnicos e educadores, as problemáticas familiares que originaram a entrada no acolhimento ainda permanecem presentes aquando a saída, especialmente se esta é decidida pelo próprio jovem ao atingir a maioridade.

Acho que nos faltam também técnicos e serviços que podem trabalhar a família. Porque as crianças são retiradas, e o problema da criança está resolvido entre aspas. Mas as limitações e as problemáticas das famílias mantêm-se e essas famílias precisam de ser trabalhadas enquanto a criança é retirada. (...) Ou seja, a criança é retirada mas a família não é trabalhada e, e... e há poucos serviços que realmente têm técnicos suficientes para isso. (Técnica)

Por outro lado, a falta de articulação e trabalho em rede entre as diferentes entidades intervenientes nos processos de acolhimento supõe que as decisões são, em algumas circunstâncias, imprevistas e pouco preparadas, especialmente nos casos em que se interpõe uma decisão judicial.

\section{4. O acompanhamento após a saída}

O regresso da criança junto da família abre uma nova etapa com novos desafios, alterando, na perspetiva dos profissionais, as rotinas e a organização familiar. Isto supõe uma nova adaptação da família.

Os participantes consideram que, deste modo, podemos falar num momento complexo onde ainda podem não estar bem resolvidos as dificuldades que originaram o acolhimento. De facto, opinam que o acolhimento pode, em alguns casos, ter colocado durante meses ou anos a criança em outro ambiente mais seguro, mas ao regressar para casa, os problemas recomeçam e as situações de perigo podem continuar a existir.

Porque enquanto a criança está aqui e que há o acompanhamento da criança e o acompanhamento dos pais, tudo rola dentro de tudo o que é normal. A partir do momento que acaba a medida, tudo volta outra vez. (Educadora) 
Os profissionais expressam que frequentemente as crianças e famílias experimentam uma rutura no acompanhamento técnico, sendo que em ocasiões até cessa o apoio de qualquer medida no meio natural de vida. Isto supõe uma falta de suporte imediato nos momentos de necessidade, sendo que a relação formal com a casa de acolhimento termina e a nível global dos serviços experimenta-se uma falta de recursos para o acompanhamento e a intervenção após a saída da criança do recurso residencial.

Fazer aqui este acompanhamento pós-saída e perceber se é preciso mais uma ajuda... Porque às vezes há aqui uma rutura. Estavam aqui e estavam acompanhados desta forma, e depois vão a casa e ficam sem este acompanhamento. (Técnica)

Os profissionais das casas de acolhimento consideram, porém, que sentem a necessidade de consolidar o trabalho realizado durante o tempo de intervenção e reconhecem que, num modo mais informal, ainda mantêm o vínculo criado com as crianças e jovens acolhidos após a sua saída. Não acontece igual com os progenitores, considerando que o envolvimento destes se mantém enquanto existe algum tipo de acompanhamento mais formal.

A rede de apoio à família tenta ser reforçada, por parte dos profissionais, com a família alargada, mas quando esta foi mencionada sempre foi considerada como apoio para os casos em que as garantias da família nuclear não eram plenas.

Finalmente, os profissionais mostram-se conscientes das experiências que têm lugar durante o processo de reunificação familiar, seja nas crianças ou nos progenitores, e cuja manifestação mais sensível é a motivação de não repetir as situações que conduziram ao acolhimento para evitar a reentrada no acolhimento. Porém, estas forças motivacionais podem chocar com a influência que o meio, na perspetiva dos profissionais, ainda pode exercer sobre as famílias e o sucesso dos processos.

\section{Discussão e considerações finais}

As conceções sobre o acolhimento residencial de crianças e jovens em perigo experimentou grandes transformações durante os últimos anos, reconhecendo-se hoje que a natureza desta medida de proteção tem todas as potencialidades para prevenir o agravamento de situações de negligência ou maltrato e, simultaneamente, promover fatores de proteção e bem-estar de crianças, jovens e famílias.

Os modelos sistémicos e as teorias sobre o risco psicossocial permitiram também identificar processos de resiliência individual e familiar. Este paradigma e a construção efetiva de planos de ação individuais que considerem objetivos e intervenções específicas neste sentido contribuem para a qualidade 
do serviço residencial (Del Valle et al., 2012). A programação e supervisão adequada dos PSEI, em alguns casos ausente, pode constituir uma ferramenta para organizar o trabalho com a família, durante o acolhimento e algum tempo após a saída. De igual modo, o contributo das teorias da resiliência familiar, apoiadas na consideração das forças que possui a família, salienta as vantagens de integrar os pais e mães no processo de acolhimento como elementos facilitadores do regresso da criança ou do jovem para a família biológica e consolidação da reunificação familiar (Lietz e Strength, 2009; Martín et al., 2015).

O papel dos profissionais envolvidos no acolhimento residencial de crianças e jovens em perigo resulta fundamental para a integração da família e a adesão progressiva à medida. Porém, grande parte do trabalho residencial é focado normalmente na criança, esquecendo a complexidade dos sentimentos, as inseguranças e as dificuldades com que os progenitores devem lidar na separação (Balsells et al., 2013). A criação progressiva de relações de confiança entre os progenitores e os profissionais das casas de acolhimento transforma-se rapidamente em pronóstico de sucesso ao facilitar o estabelecimento de relações de ajuda e apoio mútuos em benefício da criança ou do jovem acolhido (Lietz, 2011; Lietz e Strength, 2009). Porém, a intervenção centrada na família no contexto do acolhimento torna-se complexa ao colidir com as rotinas das casas e, por vezes, supõe a necessidade de criar recursos complementares para mediar conflitos que podem surgir (Small, Bellonci e Ramsey, 2014).

No caso das visitas e contactos, estes são os principais momentos de convívio, relação e interação entre as crianças e os progenitores. Todavia, além dos benefícios emocionais que proporcionam, os profissionais admitem usar este recurso não unicamente como modo de assegurar a manutenção dos laços relacionais, mas também como um modo de avaliar e supervisionar os processos relacionais da família e as competências dos pais e das mães. A falta de recursos humanos que permitam um acompanhamento mais aprofundado, de aconselhamento e apoio de cariz psico e socioeducativo, traduzem-se em mecanismos de supervisão, que levam mais frequentemente a constatar as deficiências em lugar de apoiar e intervir na criação de recursos pessoais que permitam aos progenitores ganhar competências e superar as inseguranças e medos próprios da separação. Apesar de não ser verbalizado pelos profissionais, esta realidade permite também apontar a necessidade de formação sobre a reunificação familiar e a intervenção com famílias, dotando-os de competências e materiais para trabalhar com estas, quer através de intervenções individuais, quer em grupo.

Igualmente críticas são as necessidades de apoio e suporte, que se mantêm após a saída da criança ou do jovem da casa de acolhimento. No entanto, os profissionais referem uma rutura no modo em como as famílias 
são acompanhadas e dos recursos que são disponibilizados. É referida a tentativa de promover o acesso das famílias aos recursos comunitários escolares e de saúde, confiando que os serviços e técnicos externos possam intervir no contexto em que se inserem as famílias. A rede de apoio informal é de grande importância para o sucesso da reunificação (Balsells et al., 2014), mas aparece pouco referida exceto como recurso para compensar possíveis défices que se identifiquem na família de origem aquando a saída.

Como principais limitações do estudo, é possível destacar que os resultados não são generalizáveis ao tratar-se de uma amostra não-probabilística. Do mesmo modo, as casas de acolhimento participantes pertenciam todas ao distrito de Braga, sendo que o estudo não abrange a realidade no país. Por outro lado, o tamanho reduzido da amostra não permite analisar as diferentes perceções entre os técnicos e os educadores. Adicionalmente, seria importante poder incluir a visão de outros profissionais do sistema de proteção não pertencentes às casas de acolhimento ou a análise empírica das intervenções desenhadas nos PSEI para promover a reunificação familiar.

\section{Conclusão}

A análise específica dos discursos dos profissionais das casas de acolhimento revela primeiramente uma necessidade de ampliar os recursos humanos e de formação. Esta última deve centrar-se especialmente na sensibilização e flexibilização dos recursos residenciais para poder incluir as famílias nas rotinas e na intervenção. Além de que é salientada a necessidade de desenhar procedimentos e planos de ação que, fundamentados na teoria, permitam o trabalho técnico sistemático e a recolha de evidências.

Acresce também a consciência da importância das intervenções facilitadoras da reunificação familiar, completando o trabalho individual e grupal com as famílias, tanto com as crianças como com os progenitores. E no contexto de outras intervenções de apoio social ou de cariz terapêutico, estas intervenções de natureza psico e socioeducativas devem articular-se às restantes, contribuindo para a partilha de experiências entre as famílias.

Finalmente, deve ser reconsiderado o modo como são acompanhadas as famílias após o acolhimento, favorecendo um trabalho em rede e uma reflexão sobre os recursos que são disponibilizados para o apoio nas fases imediatas após a saída do recurso residencial. Neste sentido, é possível realizar uma reflexão sobre o papel que podem ter as casas de acolhimento para continuar o trabalho realizado e o modo de dotação dos recursos técnicos que permitam este acompanhamento após a saída. 


\section{Referências bibliográficas}

ARIZMENDI, José, ALMEIDA, Ana (2017), "Reunificação familiar e acolhimento residencial em Portugal-Norte: visões dos intervenientes", Revista de Estudios e Investigación en Psicología y Educación, Extr. (05), 96-101, disponível em: https://doi.org/10.17979/ reipe.2017.0.05.2371 [consultado em: 20/12/2017]

BALSELlS, Maria Àngels, PASTOR, Crescencia, AMORÓS, Pere, MATEOS, Ainoa, PONCE, Carmen, NAVAJAS, Alicia (2014), "Child Welfare and Successful Reunification through the Socio-Educative Process: Training Needs among Biological Families in Spain", Social Sciences, 3 (4), 809-826, disponível em: https://doi.org/10.3390/socsci3040809 [consultado em: 18/12/2017]

BALSEllS, Maria Àngels, PASTOR, Crescencia, MATEOS, Ainoa, VAQUERO, Eduard, URREA, Aida (2015), "Exploring the needs of parents for achieving reunification: The views of foster children, birth family and social workers in Spain", Children and Youth Services Review, 48, 159-166, disponível em: https://doi.org/10.1016/j.childyouth.2014.12.016 [consultado em: 20/12/2017]

BALSEllS, Maria Àngels, PASTOR, Crescencia, MOLINA, Maria Cruz, FUENTESPELÁEZ, Nuria, VAQUERO, Eduard, MUNDET, Anna (2013), "Child welfare and successful reunification: Understanding of the family difficulties during the socio-educative process", Revista de Cercetare si Interventie Sociala, 42, 228-247.

BIEHAL, Nina (2007), "Reuniting children with their families: Reconsidering the evidence on timing, contact and outcomes", British Journal of Social Work, 37 (5), 807-823, disponível em: https://doi.org/10.1093/bjsw/bcl051 [consultado em: 18/12/2017]

BRAVO ARTEAGA, Amaia, DEL VALLE, Jorge Fernández (2001), "Evaluación de la integración social en acogimiento residencial", Psicothema, 13(2), 197-204.

CARNOCHAN, Sarah, LEE, Chris, AUSTIN, Michael J. (2013), "Achieving Timely Reunification: Performance Pointers", Journal of Evidence-Based Social Work, 10 (3), 179-195, disponível em: https://doi.org/10.1080/15433714.2013.788948 [consultado em: 20/12/2017]

DEL VALLE, Jorge Fernández (2009), "Cómo potenciar la reunificación familiar desde los Centros y Hogares de Protección", in Jorge F. del Valle e Amaia Bravo (org.), Intervención socieducativa en acogimiento residencial, Santander, Gobierno de Cantabria, 117-132.

DEL VALLE, Jorge Fernández, BRAVO, Amaia (2007), SERAR :Sistema de Evaluación y Registro en Acogimiento Residencial, Oviedo, Nieru.

DEL VALLE, Jorge Fernández, BRAVO ARTEAGA, Amaia, MARTÍNEZ HERNÁNDEZ, María, SANTOS GONZÁLEZ, Iriana (2012), Estándares de calidad en acogimiento residencial: EQUAR Informes, estudios e investigación, Madrid, Ministerio de Sanidad, Servicios Sociales e Igualdad.

DELFABBRO, Paul H., BARBER, James G., COOPER, Lesley (2002), "The Role of Parental Contact in Substitute Care", Journal of Social Service Research, 28 (3), 19-39, disponível em: https://doi.org/10.1300/J079v28n03_02 [consultado em: 20/12/2017]

DEPARTMENT OF HEALTH (2000), Framework for the Assessment of Children in Need and Their Families, London, The Stationery Office.

DÉPREZ, Alexandra, WENDLAND, Jacqueline (2015), "La visite parentale chez l'enfant placé, une revue de la littérature", Annales Medico-Psychologiques, 173 (6), 494-498, disponível em: https://doi.org/10.1016/j.amp.2013.07.009 [consultado em: 18/12/2017]

HAYES, Andrew F., KRIPPENDORFF, Klaus (2007), "Answering the Call for a Standard Reliability Measure for Coding Data", Communication Methods and Measures, 1 (1), 77-89, disponível em: https://doi.org/10.1080/19312450709336664 [consultado em: 20/12/2017] 
INSTITUTO DA SEGURANÇA SOCIAL, I. P. (2017), CASA 2016 - Relatório de Caracterização Anual da Situação de Acolhimento das Crianças e Jovens, Lisboa, Instituto da Segurança Social, I.P.

KNORTH, Erik J., KNOT-DICKSCHEIT, Jana, THOBURN, June (2016), "Supporting children when providing services to families experiencing multiple problems", International JournaI of Child and Family Welfare, 16, 2-10.

LEATHERS, Sonya J. (2002), "Parental visiting and family reunification: Could inclusive practice make a difference?", Child Welfare, 81(4), 595-616.

LIETZ, Cynthia A. (2011), "Theoretical adherence to family centered practice: Are strengths-based principles illustrated in families' descriptions of child welfare services?", Children and Youth Services Review, 33(6), 888-893, disponível em: https://doi.org/10.1016/j.childyouth.2010.12.012 [consultado em: 20/12/2017]

LIETZ, Cynthia A., LACASSE, Jeffrey R., CACCIATORE, Joanne (2011), "Social Support in Family Reunification: A Qualitative Study", Journal of Family Social Work, 14 (1), 3-20, disponível em: https://doi.org/10.1080/10522158.2011.531454 [consultado em: 18/12/2017]

LIETZ, Cynthia A., STRENGTH, Margaret (2009), "Stories of Successful Reunification : A Narrative Study of Family Resilience in Child Welfare", Families in Society, 92 (2), disponível em: https://doi.org/10.1606/1044-3894.4102 [consultado em: 20/12/2017]

MALUCCIO, Anthony N., AINSWORTH, Frank (2003), "Drug Use by Parents: A Challenge for Family Reunification Practice", Children and Youth Services Review, 25 (7), 511-533, disponível em: https://doi.org/10.1016/S0190-7409(03)00042-2 [consultado em: 20/12/2017]

MARTín, Juan Carlos, ALMEIDA, Ana Maria Tomás, CABRERA, Eduardo, MIRANDA, Cristina, RODRIGO, María José (2015), "La evaluación de riesgos y fortalezas en Parentalidad Positiva", in María José Rodrigo, María Luisa Máiquez, Juan Carlos Martín, Sonia Byrne, e Beatriz Rodríguez (org.), Manual práctico de parentalidad positiva, Madrid, Editorial Síntesis, 45-65.

SEN, Robin (2010), "Managing contact in Scotland for children in non-permanent out-of-home placement", Child Abuse Review, 19 (6), 423-437, disponível em: https://doi.org/10.1002/ car.1139 [consultado em: 18/12/2017]

SEN, Robin, BROADHURST, Karen (2011), "Contact between children in out-of-home placements and their family and friends networks: a research review", Child and Family Social Work, 16 (3), 298-309, disponível em: https://doi.org/10.1111/j.1365-2206.2010.00741.x [consultado em: 20/12/2017]

SMALL, R. W., BELLONCI, C., RAMSEY, S. (2014), "Creating and maintaining family partnerships in residential treatment programs: Shared decisions, full participation, mutual responsibility", in J. W. Whittaker, Jorge Fernández Del Valle, e L. Holmes (org.), Therapeutic residential care with children and youth: Developing evidence-based international practice, London and Philadelphia, 156-171. 